\title{
CULTURAL DIVERSITY AND ITS IMPLICATION ON PARENTS' ATTITUDES TOWARD THEIR CHILD LEARNING DISABILITY - AN OUTLINE OF A RESEARCH STUDY
}

\begin{abstract}
Gonen-Avital Shiri, Cultural Diversity and its Implication on Parents' Attitudes Toward their Child Learning Disability - An Outline of a Research Study [Różnorodność kulturowa i jej implikacje względem postaw rodziców wobec trudności w uczeniu się ich dzieci - przyczynek do badań]. Studia Edukacyjne nr 40, 2016, Poznań 2016, pp. 353-377. Adam Mickiewicz University Press. ISSN 1233-6688. DOI: $10.14746 /$ se.2016.40.19
\end{abstract}

Background: Israel is a land of immigration - a multicultural society with a mosaic of different cultures. There are four maim ethnic groups in Israel: "Sabre" (born in Israel), Arabs, Russian, and Ethiopian.

The main aim of this article is to present the connection between two main issues: Culture Diversity and the Attitudes of Israeli parents to children with Learning Disability (LD). This article stems from a deep and extensive dissertation research on parents' attitudes toward their child Learning Disability in Israel and it is an outline of the research study.

Family: The resilience and strength of the family depend on the social, cultural and personality of the family in general, and parents in particular. The parents play a crucial role in facilitating and maintaining wellness in children with developmental disorders.

Learning Disability: Today, in the modern world, in the information era, when processing information skills are necessary in everyday life, Learning Disability turn into a widespread phenomenon. Learning disability is a general term that refers to a heterogeneous group of disorders manifested in the acquisition and operation of attention, speaking, reading, writing, or mathematical abilities. Within the Hebrew students in Israel (years 2013-2014), 10.10\% are diagnosed with learning disability.

In summary, due to the fact that Israel is an immigration country, it is vital to research the implication of parents' attitudes toward their child Learning Disability for the wellbeing of the family and the society.

Key words: parents, learning disability, cultural diversity

Background: Understanding and recognizing the sociological major impact on parental attitudes toward their child's learning disability can make 
a difference in the perception of the educational system. as well as will help to build a trust relationship between the parents and the educational institution. Characterizing the culture differences is new and significant information that will have implications that can be implemented in the field of special education. The main aim of the article is to present the connection between two main issues: Culture Diversity and the Behavior of Israeli parents to children with Learning Disability (LD), in relation to attitudes and coping. This article stems from a deep and extensive dissertation research on parents' attitudes toward their child Learning Disability in Israel and it is presented as an outline of the research study.

\section{Learning disability}

Learning is the way of acquiring or modifying, new or existing knowledge, behaviors, skills, and values. The Learning method is involves with different types of information and is attributed to higher cognitive function and most complex of the brain. Learning may be also viewed as a process that produces changes and the changes are relatively permanent. It is important, before defining learning disability (L.D), to distinguish between learning disability and learning difficulties. ${ }^{1}$ Some people may have difficulties from learning disabilities, and many others, will only have a single expression that may have very little effect on other areas of their lives.

It is well known, that the modern society today is based on processing information. An information society is a society where the creation, uses, and integration of information is expressed by significant economic, political, and cultural activity. The Industrial Revolution that started at the mid eighteen century is acceptable name for the technological changes. The Industrialization caused changes in the perception about the importance of education, especially reading and writing, and the most significant outcome is that the children began to go into school instead of going to work. Today, in the modern society when everything is based on information technology (IT), it can be assumed that if the child with learning disability has no skills to work IT knowledge, the child will be socially disabled. In light of this, not all learning gap, is due to a learning disability, such a gap may stem from didactic failure, non-exposure to spoken or written language, low motiva-

\footnotetext{
${ }^{1}$ M. Brown et al., Learning Disability Liaison Nursing Services in south-east Scotland: a mixed-methods impact and outcome study, Journal of Intellectual Disability Research, 2012, 56(12), p. 1161-1174.
} 
tion, lack of opportunities, and some emotional aspects (family circumstances, traumas). It may be possible to reduce the gap between the student and the learning environment, with reference to the provision of external causes that contributed to the difficulty, or by providing training and assistance in learning. Many students, especially the younger age groups (grades A - B) sometimes require a little more time to acquire these skills and these transient problems in learning, are representing various normal nervous system maturities that exist between humans. ${ }^{2}$

Learning disabilities (L.D) is a classification that includes a number of areas where a person finds it difficult to learn the routine way. People with learning disabilities are facing unique challenges that can be expressed throughout the lifespan, depending on the type and severity of disability. The National Joint Committee Learning Disabilities (NJCLD, 2010), used the term 'learning disability' to indicate a discrepancy between a child's capability to learn, and his or her level of achievement. In the ICD-10, ${ }^{3}$ LD is described as specific developmental disorders of scholastic skills (code: F81). According to domain-specific contents, a specific reading disorder (F81), it is also called developmental dyslexia, a specific spelling disorder (F81.1), and a specific disorder of arithmetic skills (F81.2), also called dyscalculia.

A learning disability is expressed by: A. Relevant academic achievement that is significantly lower than expected from the child's academic age. B. IQ level has to be in the normal range or above average (e.g., the average IQ grade is 100), and the score on the achievement test has to be considerably lower than the score on the IQ test (e.g., according to the research criteria of the ICD-10, the discrepancy should be of at least two standard deviations).

Although learning disabilities may occur adjacent to other disorders such as sensory disorders, mental retardation, serious emotional disturbance, or are accompanied by of external influences (such as cultural differences, educational deficits), they are not the result of these factors. ${ }^{4}$ Learning disability can be also explained as a disorder that affects the ability to process what they saw, or heard, or contact the information that comes from different parts of the brain.

The LD definition chosen for this research, is similar to the definition proposed by the Ministry of Education in Israel, "A person is diagnosed as

\footnotetext{
2 M. Danino, Z. Shechtman, Superiority of group counseling to individual coaching for parents of children with learning disabilities, Psychotherapy Research, 2012, 22(5), p. 592-603.

3 World Health Organization, The ICD-10 classification of mental and behavioral disorders: clinical descriptions and diagnostic guidelines, Geneva 1992.

${ }^{4}$ I. Modlinger, Liku'ye limida shel hasafa ha'ktuvah [Learning Disabilities of Written Language], 2005 (Hebrew) http:/ / techedu.huji.ac.il/learning/language/language5.htm
} 
having learning disabilities, when the achievement on standardized tests in reading, mathematics, or written expression, given to him individually, are significantly lower than expected according to age, education level and IQ, and his learning difficulties cause interference significant in his academic achievements or daily activities that require reading skills other, account or writing". 5

The most important assumption about etiology of L.D is that some children have biologically-based cognitive deficits or cognitive dysfunctions that hinder their adequate acquisition of fundamental academic skills. ${ }^{6}$ However, it is not so simple to empirically identify those causes. One of these reasons is that there is not enough knowledge how cognitive dysfunctions are related to specific LD. Although the literature has identified cognitive deficits as closely associated with specific LDs7 it remains unclear whether the identified cognitive deficits are causal factors or a mere consequence or even an intervening variable of the disability. ${ }^{8}$

Learning disabilities can be also traced to brain development, both before and after birth. For this reason, problems such as low birth weight, lack of oxygen, or premature birth may have something to do with learning disabilities. Young children who receive head injuries may also be at risk of developing learning disabilities. ${ }^{9}$ Learning disability can be also influenced by environmental impacts. Children with LD have poorer health than their non-disabled peers (Emerson, 2013). They are also more likely to be exposed to a wide range of environmental danger in childhood that can have an impact on health and well-being across the life course.

It is common to divide the characteristics of learning disabilities into two main groups: A. Cognitive characteristics associated with academic abilities disorders, B. Emotional and social characteristics associated with lack of social abilities.

Cognitive Characteristics: LD is expressed in data processing and congenital strategies (Heiman, 2005). The cognitive aspect is reflected in 7 possi-

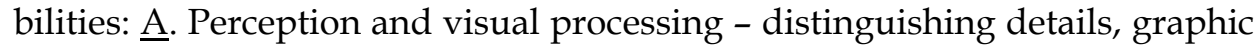

${ }^{5}$ Ministry of Education, Israel, 1988.

${ }^{6} \mathrm{G}$. Büttner, M. Hasselhorn, Learning disabilities: Debates on definitions, causes, subtypes, and responses, International Journal of Disability, 2011, 58(1), p. 75-87.

${ }^{7} \mathrm{~K}$. Landerl et al., Dyslexia and dyscalculia: Two learning disorders with different cognitive profiles, Journal of Experimental Child Psychology, 2009, 103(3), p. 309-324.

8 F.R. Vellutino et al., Response to intervention as a vehicle for distinguishing between children with and without reading disabilities evidence for the role of kindergarten and first-grade interventions, Journal of Learning Disabilities, 2006, 39(2), p. 157-169.

${ }_{9}$ M. Margalit, H. Tur-Kaspa, LD: A multi-dimensional neurodevelopment model, Psychology, 1998, 7, p. 64-76. 
symbols, directions, character and background, complete vision and its

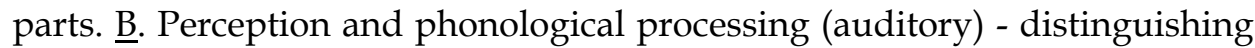
between similar sounds, break down into syllables, opens / closes sound in

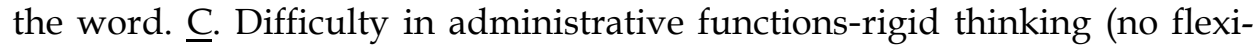

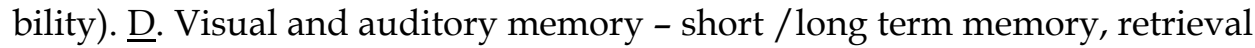
memory, an active memory. Language - pronunciation, vocabulary, syntax, morphology, pragmatics, semantics. E. Motor Gross Motor Skills function and gentle function. $\underline{F}$. Imperfection in orientation in time and space. G. Complex organization problems - proper organizing and scheduling. These difficulties often associated with emotional and behavioral aspects that are the result of the disability, but they are not the cause for it. It is impossible to cure the primary disability that originates from the central nervous system defects, but it is possible to improve it in some degree.

Social Characteristics - include repository of behaviors, verbal and nonverbal that are acquired during socialization. Good social skills built on a set of combined acceptable social skills on an ongoing basis, in accordance with the rules that lead to positive outcomes for individuals and for those who communicate with them. ${ }^{10}$ Due to the complex learning difficulties with which children with learning disabilities face on a daily basis, some socioemotional difficulties can be identified by low self-confidence, low selfesteem, frustration and difficulty to deal with obstacles. The ability to identify properly social situation, to understand the true intentions, thoughts and emotions of the students is the basis for creating interpersonal relationships intact. L.D children cannot practice the social skills required to conduct social acceptability because they lack interpersonal relationships and might feel social rejection.

In conclusion, there are many children who struggle daily to communicate and make sense of their social world. As the ministry of education is committed to the success of all students, these children should get help to build the social skills they need to succeed in school and in life. The researcher believes that the Emotio-Socio and the Cognitive aspects are quite bonded, influence each other and cannot be divided. That is why the education process of the LD child, must give solution to both aspects.

The LD children are not a homogeneous group. Due to disagreement among researchers, in connection with the definition and characteristics of the population, attempts were made to define subtypes according to the unique difficulties for any type such as: difficulty in reading, in writing, and

\footnotetext{
${ }^{10}$ I. Modlinger, Liku'ye limida shel hasafa ha'ktuvah [Learning Disabilities of Written Language], 2005 (Hebrew) http:/ / techedu.huji.ac.il/learning/language/language5.htm
} 
in mathematics. Each type of learning disability has its own characteristics. Every child who has L.D have a special combination of abilities and deficits, and there are some common types of learning disability appearance and the most common are three main types of disorders: Dyslexia Dysgraphia, and Dyscalculia that are most obvious and usually, they revolve around reading, writing, or math. ${ }^{11}$

Dyslexia (reading disabilities): Dyslexia is a reading disability that prevents, or inhibits the acquisition of reading, depending on reader's cognitive ability. Dyslexia is most common in the LD population and can be expressed in many grades. The reasons the appearance of dyslexia is specific disruptions and processes that interfere with accurate processing of stimuli, and prevent providing a necessary response to correct and to be understandable.

Dysgraphia: Dysgraphia means difficulty in writing. Writing requires a considerable investment of energy, persistence and time. This disorder causes significant difficulties in acquiring academic achievement, or performance of daily functions associated with writing skills. ${ }^{12}$

Dyscalculia is a defect in the perception of calculations in the field of quantitative thinking and mathematics. The term Dyscalculia comes from Greek and Latin and means "counting badly". This deficiency can be expressed in difficulty to calculate arithmetic exercises. In addition there are more 2 types of Learning Disability like: Non-verbal learning disabilities and Attention deficit hyperactivity disorder (ADHD).

Non-verbal learning disabilities: LD is identified in the population, as having a nonverbal problem such as solving a distinction between left and right, identifying directions, and so on. Non-verbal learning disabilities include Dyspraxia, Disnomia and Disorientation. Dyspraxia is considerable difficulty in tasks performance, in planning process forward, motor skills such as painting. Disnomia, which is a difficulty in remembering names and words. Disorientation - space perception impairment, including difficulty orientation such as directions, and schedules. ${ }^{13}$

Attention deficit hyperactivity disorder (ADHD): ADHD is a neuropsychiatric problem that has significant problems with executive functions (eg, control of attention, and inhibitory control) that cause attention disor-

11 G. Kemp, M. Smith, J. Segal, Learning Disabilities and Disorders. Retrieved March 29, 2015, from http://www.helpguide.org/articles/learning-disabilities/learningdisabilitiesand-disorders.htm

12 J.E. Spector, Instability of double-deficit subtypes among at-risk first grade readers, Reading Psychology, 2005, 26(3), p. 285-312.

${ }^{13}$ R. Shimshoni, A. Brenner, Learning skills for learners with learning disabilities, The new studio echo, 2004 (Hebrew). 
ders, hyperactivity, and impulsivity, and is not suitable for the age of the person. ${ }^{14} \mathrm{ADHD}$ is expressed when a person cannot focus on the process of concentration over a specific time period.

\section{Inclusion, Assessment, Diagnosis and Placement of a child having LD}

The main aim of educators and parents is to support the L.D children, to be a fully part in their communities, and it requires high quality of strategy. There are many strategies that will help to support children in early childhood settings. The National Association for the Education of Young Children (NAEYC) define it as: "Early childhood inclusion embodies the values, policies, and practices that support the right of every infant and young child and his or her family, regardless of ability, to participate in a broad range of activities and contexts as full members of families, communities, and society" ${ }^{15}$

According to 2014 data from the Central Bureau of Statistics in Israel, ${ }^{16}$ 108,217 special need students studied in elementary school education, grades A to F. Out of this children, 64,096 are diagnosed as having LD. In Israel, the children are embedded into three educational options: A. integrated into a regular class $(65.5 \%)$, B. learning in small classes in a regular school $(28.2 \%)$ or C. learning in special education schools (5.5\%).

As it was noted ahead when discussing the LD definition, the criteria are not sufficient enough to differentiate the learning disability, so before going into the in-depth diagnosis of the LD, a child's assessment should be done. The main aim of the assessment is to determine the child's specific learning strengths and needs, and to determine whether or not the child is eligible for special education services. Many professionals from different fields are participating in the decision about the way of the child support, as it can be seen in figure 1. all these factors are part of a team, often referred to as a multidisciplinary team, which tries to determine what, if any, disability is present in a student.

\footnotetext{
${ }^{14}$ K.W. Lange et al., The history of attention deficit hyperactivity disorder, ADHD Attention Deficit Hyperactivity Disorders, 2010, 2(4), p. 241-255; A. Sroubek, M. Kelly, X. Li, Inattentiveness in attention-deficit/hyperactivity disorder, Neuroscience Bulletin, 2013, 29(1), p. 103-110.

${ }^{15}$ NAEYC, A position statement of the National Association for the Education of Young Children Developmentally Appropriate Practice in Early Childhood Programs Serving Children from Birth through Age, 2009, p. 2, https://www.naeyc.org/files/naeyc/file/positions/PSDAP.pdf

${ }_{16}$ CBS, 2015 http://www.cdc.gov/nchs/nhis.htm http://www.cbs.gov.il/reader/?MIval=cw_usr_view_SHTML\&ID=403.
} 


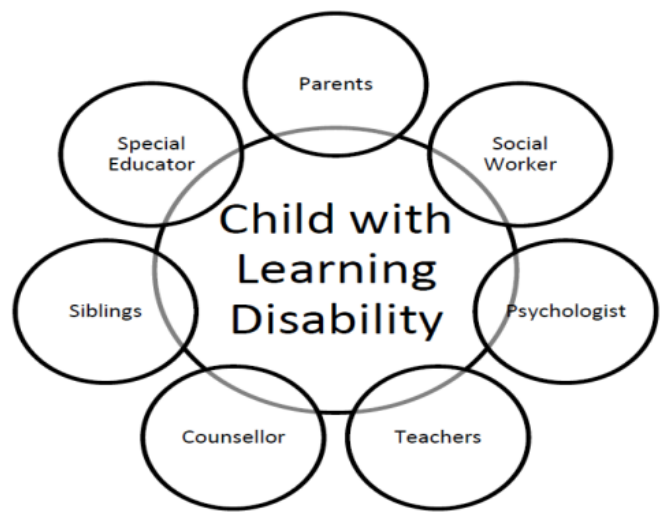

A holistic approach of teamwork by professionals and family members for the development of the Child with Learning disability

Fig. 1. A holistic approach of teamwork by professionals and family members for the development of the Child with Learning disability by Burhan \& Begum, 2015, p. 162

The next stage is making a decision concerning the where to embed the LD child. After a child who experiences difficulty in school, is tested by a licensed school psychologist, and deemed eligible for special education services, he or she is referred to a local Placement Committee, which formally decides eligibility and placement.

The decision where to embed the child with learning disability is not so simple. On the one hand, the frame of special education have more tools to help promote the child, On the other hand, there is fear of a stigma that will cling to him along with the frustration that he is "not like everyone else" and therefore the question is what is right for a child? Will he be a" lion's tail" by learning in a regular class, or will he be the "fox's head" by learning in an integrated class, or in a special education school. Danino (2012) notes that the integration policy believes in utilizing all forms of help and aid the student could receive as part of the regular classroom, by adjusting the academic requirements or with the addition of hours of instruction and care. However, when these are inadequate and educational staff finds it difficult to address as part of the regular classroom, there is concern that a significant gap that will be created. In addition, another question is raised: What is the price of integration within the framework of regular education? Does the fact that the child goes out of "normal classroom" to individual learning, affects his self-image? Is it accompanied by a sense of failure, disappointment, helplessness and frustration from the inability of the parent to help the child be "like everyone else". In light these concerns, sometimes, the parents 
are trying to avoid some of the committee recommendations and fight for the future of the child.

Finality, in order to embed the LD child in the proper place, it is necessary that the professionals will make multidisciplinary diagnosis, including a comprehensive evaluation in education psychology and medicine. Diagnosis at an early age is very important because appropriate treatment plan may reduce cumulative learning gaps and erase the negative label of the individual both in his own eyes and in the eyes of society. Margalit \& Tur-Kaspa,17 presented a Multi-dimensional development model (fig. 2.) that explain the interactions among individual characteristics (power and difficulties fields) and environmental characterization (educational and environmental). It has an important contribution to predict the student's adaptive functioning at various stages of the life cycle. A combination of empowerment and effective coping with difficulties and challenges highlights the implications for diagnosis and treatment applications. According to the proposed model, the relationship between the individual and the environment are dynamic and continuous, mutual and dependent on each other.

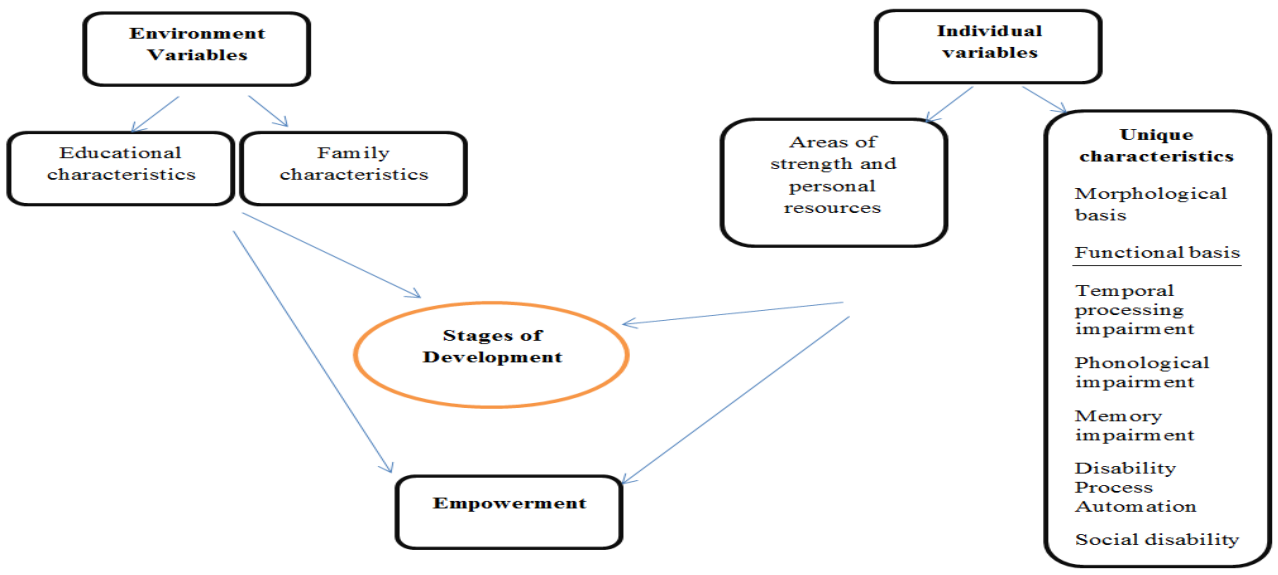

Fig. 2. Multi-dimensional development model: M. Margalit, H. Tur-Kaspa, LD: A multidimensional neurodevelopment model, Psychology, 1998, 7, p. 64-76

Learning disability in Israel: Israel is a small and complex country, within the Israeli school system reflects the Israeli society along with its his-

${ }_{17}$ M. Margalit, H. Tur-Kaspa, LD: A multi-dimensional neurodevelopment model, p. 64-76. 
torical and cultural heritage. ${ }^{18}$ Israel's population is the more educated in the world. ${ }^{19}$ The rate of those with higher education is much higher than the OECD average: $48.5 \%$ vs. $33.6 \%$. Israel ranks second in the rate of those with higher education among member States OECD after Canada. However, the statistics from OECD (2015) note that the density of Elementary education in Israel, is characterizes by larger class sizes. The class sizes in Israel are $26 \%$, larger, compared to other countries. In Israel, 26.7 students per class on average, in comparison with 21.2 students in the states OECD. There are 26.7 students per class, compared to 21.2 students on average in OECD countries.

In recent years, there has been great progress in Israel in terms of awareness, diagnosis for accommodating students with learning disabilities. Schools have already implemented procedures designed to assist in accommodating the matriculation examinations for students with learning disabilities and universities assist in implementing adjustments exams for students with learning disabilities. However, many times the resources allocated by the school to assist students with learning difficulties are not compatible with each student's needs and therefore there is a need further assistance given privately. So there is a lacks of uniform policy and procedures to be taken to fully clear their difficulties of students with learning disabilities, and there is an increased need for legislation laws and regulations that allow them to deal equally with the academic studies. ${ }^{20}$

The Ministry of Education set three different frameworks for integration of children with special needs in the education system: Inclusion, special education classes in the schools of general education and separate schools for special education. ${ }^{21} 1$. The framework of inclusion in the general schools 2. Special education classes in the schools of general education 3. separate schools for special education are for students with complex disorders. The Israeli State have obligation to fund the support services needed to the child for being included in a regular educational frameworks:

18 T.P. Gumpel, V. Sharoni, Current best practices in learning disabilities in Israel, Learning Disabilities Research \& Practice, 2007, 22(3), p. 202-209.

19 OECD, Israel population, Israel 2015, p. 223 https://www.oecd.org/israel/going-forgrowth-israel-2015.pdf

${ }^{20}$ M.J. Pitoniak, J.M. Royer, Testing accommodations for examinees with disabilities: A review of psychometric, legal, and social policy issues, Review of Educational Research, 2001, 71(1), p. 53-104.

${ }^{21}$ C. Igel, S. Malichi, Special Education Law - Social, Value-Oriented, and Professional Reflection in the Shaping of Policy, [in:] Integrating: Learning with Handicaps in the Educational Systems, Eds. S. Reiter, Y. Lazer, G. Avisar, Achva, Haifa 2007, p. 148 (Hebrew). 
Parents play a crucial role in facilitating and maintaining wellness in children with developmental disorders.22 For the child, the family is a supportive framework that protects its existence. For some parents, the child is the focus of their self-fulfillment, and serves as a protection against the basic existential anxiety, on the other hand, there are parents for whom children are burden and if those children will have LD, most likely that their parents will not give them optimal care. Managing learning disability in children affects various aspects of the parent's wellbeing who are the primary caregivers. The family role of the disabled child is vital because they ought to be the optimum environment for the development of the children. A disabled family member, usually results in some adjustments that will be done in the roles, norms, and communication, and the level of acceptance of the disability by the family, may vary from one family to the next.

The diagnosis of disability in a child is also a traumatic event. Parental reactions to their child's disability are highly individualistic. ${ }^{23}$ The type and intensity of their response depends on how parents handle crisis situations in general, stability of the marital relationships and parental aspirations. Some of the common reactions include guilt, disappointment, shame, grief, anger and disbelief.

The role of families is affected by personal, social, environmental and cultural factors. Therefore, diagnosing learning disability among one of the children, can affect family relationships. Dyson's (1996) notes that parents of children with LD, experience a lot of stress out of the situation and they focus on developing a way of coping with it. There are some families that are affected by the ongoing stress situations and find it hard to recover from crises. In contrast, other families are resourceful, flexible, having survival capability and the ability to gradually return to normal functioning. The factors that contribute to the family resilience are: the characteristics of the individual, family resources and of social support. Accordingly, Margalit \& Almougy (1991) studied 84 families of children with learning disabilities in Israel, and found a three coping patterns. A. Families in which parents reject their children, or find it difficult to come to terms with the disability. This kid is seldom much encouragement and criticism in. B. Families who are hoping that with guidance and teaching training, can promote the child to complete the gap. C. Families who receive the disability and continue the regular routine and at the same time helping their children and supporting

\footnotetext{
22 A. Simon, V. Easvaradoss, Caregiver Burden in Learning Disability, The International Journal of Indian Psychology, 2015, 2, 3(1).

${ }^{23}$ Ibidem.
} 
their particular needs. For children in such situation, there is a good chance to deal with the difficulties.

Many parents are concerned about the future of their children and are looking for help to cope better with the unknown, and to learn the proper way to take care their child disability (Heiman, 2000). Sometimes, when the parents encounter difficulties, it can open a Pandora's Box which was locked tight for years to come. This box contains a lot of anger, frustration and feelings of failure about their relationship with the school. For parents, navigating between range of service systems, designed to support their children with learning disability as they are moving from early childhood services into school-based services, can be overwhelming. ${ }^{24}$ In addition, the parental responses also vary depending on their cultural aspects, for example, Heer, Larkin, Burchess \& Rose, ${ }^{25}$ explored the cultural context of care-giving among South Asian communities caring for a child with intellectual disabilities, in United Kingdom. They recommend the service delivery to be aware to the intra-group variations in the interpretations and responses of South Asian parents. Parents of children with special needs face unique socialemotional challenges in carrying out their caregiving roles. ${ }^{26}$ Stress associated with these roles impacts parents' and special educators' health and well-being, as well as the quality of their parenting and teaching.

In addition, children with intellectual disabilities might have behavior problems, ${ }^{27}$ like aggressiveness, outbursts of anger, and Crossing Boundaries. These behavior problems interfere with the child's ability to gain from learning, ${ }^{28}$ and they also predict parental stress above the child's level of

${ }^{24} \mathrm{M}$. Janus et al., In transition: Experiences of parents of children with special needs at school entry, Early Childhood Education Journal, 2008, 35(5), p. 479-485; M. Janus et al., Starting kindergarten: Transition issues for children with special needs, Canadian Journal of Education [Revue canadienne de l'éducation], 2007, p. 628-648; B. Rous et al., The transition process for young children with disabilities: A conceptual framework, Infants and Young Children, 2007, 20(2), ${ }^{24}$ p. 135-148.

${ }^{25} \mathrm{~K}$. Heer et al., The cultural context of care-giving: qualitative accounts from South Asian parents who care for a child with intellectual disabilities in the UK, Advances in Mental Health and Intellectual Disabilities, 2012, 6(4), p. 179-191.

${ }^{26}$ R. Benn, Mindfulness training effects for parents and educators of children with special needs, Developmental Psychology, 2012, 48(5), p. 1476.

$27 \mathrm{~V}$. Totsika et al., A population-based investigation of behavioral and emotional problems and maternal mental health: Associations with autism spectrum disorder and intellectual disability, Journal of Child Psychology and Psychiatry, 2011, 52(1), p. 91-99.

${ }^{28}$ C. Roberts et al., Early intervention for behaviour problems in young children with developmental disabilities, International Journal of Disability, Development and Education, 2003, 5, p. 275-292; T. Heiman, An examination of peer relationships of children with and without attention deficit hyperactivity disorder, School Psychology International, 2005, 26(3), p. 330-339; A. After et. al., Psychiatry of the child, 1999. 
developmental delay or cognitive status. ${ }^{29}$ Viewing the child's disability as the cause for problematic behavior has positive effects for the parent in reducing guilt and anxiety. Jacobs, Woolfson, and Hunter, ${ }^{30}$ explored parents' causal beliefs and attributions for their child behavior, and they note that parents of children with intellectual disabilities do not solely interpret their child's behavior through the intellectual disabilities but incorporate the environment and causes and attributions that are not related to the intellectual disabilities, however, they claim that the environment also plays a part, like placing restrictions that prevent people with disabilities from participating in society . It is also important to find out, how the parents feel responsible for their child's behavior, if the child is viewed as unable to control his behavior, it cannot be seen as the parent's mistake; therefore, the parent feels less responsible for their child's behavior. Subsequently, there are some interesting questions about the etiology of behavioral disorders and learning disability context. Is behavioral disorder is a minor problem or is accompanied by LD? Whether severe behavioral disorder worsens the learning disability, or a combination of learning disabilities and behavioral disorder may make it difficult for the child. ${ }^{31}$ In that context, Cornwall \& Bawden ${ }^{32}$ argue that learning disabled child that experiences continuous failures and have a feeling of low self-esteem and is frustrated from the situation, may adopt impaired behavioral patterns.

In sum, viewing the intellectual disabilities as the main cause of different behavior, may lead to causal attributions that do not support effective parenting. If the parents believe that their child behavior is uncontrollable and the behavior is fixed, it could lead them to feel unmotivated and less responsible for addressing child behavior. ${ }^{33}$ That is why, a child's growth and development depends heavily on the different aspects of the environment. Parents have an exceptional influence on their child's growing years. Parental stress was explored with emphasis on the various psychological aspects,

29 S.S. Hall, D.D. Burns, A.L. Reiss, Modeling family dynamics in children with Fragile X syndrome, Journal of Abnormal Child Psychology, 2007, 35, p. 29-42.

${ }^{30}$ M. Jacobs, L.M. Woolfson, S.C. Hunter, Attributions of Stability, Control and Responsibility: How Parents of Children with Intellectual Disabilities View their Child's Problematic Behaviour and its Causes, Journal of Applied Research in Intellectual Disabilities, 2016, 29(1), p. 58-70.

31 T. Heiman, Friendship quality among children in three educational settings, Journal of Intellectual and Developmental Disability, 2000, 25(1), p. 1-12.

32 A. Cornwall, H.N. Bawden, Reading Disabilities and Aggression A Critical Review, Journal of Learning Disabilities, 1992, 25(5), p. 281-288.

${ }^{33}$ M. Jacobs, L.M. Woolfson, S.C. Hunter, Attributions of Stability, Control and Responsibility. 
without enough focus on the sociological aspect like culture influence and parent ways of struggling. There is not enough data about the parents' cultural diversity and their way of struggling with their child disability, which is an important part of the child's environment. Identifying and managing parental distress and other difficulties that they face may help increase acceptance of the child's difficulty for the benefit of their child and the whole society.

\section{Cultural diversity}

Intercultural learning is an area of research, study and application of knowledge about different cultures, their differences and similarities. On the one hand, it includes a theoretical and academic approach like Dimensions of Culture by Geert Hofstede (2011). On the other hand, it comprises practical applications such as learning to negotiate with people from different cultures, living with people from different cultures, living in a different culture and the prospect of peace between different cultures. Currently, intercultural learning is a topic which receives much interest. This is mainly due to the rise of cultural studies and globalization. Culture has become an instrument for social interpretation and communicative action. Intercultural learning is primarily important in the context of the foreign language classroom.

Symbolic interactionism is a sociological perspective which developed by George Herbert Mead and Charles Horton Cooley around the middle of the twentieth century, and it continues to be influential in some areas of the discipline. It is particularly important in microsociology and social psychology. The term "symbolic interactionism" has come into use as a label for a relatively distinctive approach to the study of human life and human conduct. ${ }^{34}$ With symbolic interactionism, reality is seen as social, developed interaction with others. Most symbolic interactionists believe a physical reality does indeed exist by an individual's social definitions, and that social definitions do develop in part or relation to something "real". People thus do not respond to this reality directly, but rather to the social understanding of reality; i.e., they respond to this reality indirectly through a kind of filter which consists of individuals' different perspectives.

${ }^{34}$ H. Blumer, Symbolic interaction: perspective and methods, New York 1969 
Cultural values among different cultures influence the relationship with providers of care. Katznelson, 35 notes that multiculturalism in education raises prejudices and stereotypes (conscious and sub-conscious) that practitioners (teachers, principals, psychologists) feel for patients of different origin. Nakash, Levav and Gal, (2012) found that the ethnic identity led to the fact that patient's caregivers respond less favorably to the patient of other origin and rate it as less collaborator. It is also widely used example of diagnosing children with proper tools: intelligence tests used in USA, contain questions "Who was the first president of USA". Those types of questions have to be adjusted to the different cultures, as it is can be understood that due to culture diversity, not everyone have to know it.

Harry, ${ }^{36}$ claims that attention to the issue of culture and its relationship to the families of children with a learning disability is relatively new and can be examined in light of the three approaches in relation to the timeline: $\mathbf{A}$. In the 70s, the approach toward the caring for children with L.D was more psychoanalytic and one of the ways in which the problem was dealt was - the promotion of parent as educator: behavioral training program. B. In the 80s, the approach was to treat parents as partners to the professionals. C. Today, the current approach emphasizes cultural diversity, the researchers are not staying in the mainstream, and they are exploring different cultural backgrounds populations that represent different behaviors.

As it can be seen, the culture of the country has a great influence on the determination of all children through education and special education in particular and it can be noted that the awareness for the Cultural diversity concerning learning disability is growing and it is an obligation to research it.

\section{The state of Israel - Is it "a melting pot" or "salad bowl", or "mosaic"?}

Hofstede (2015) claim that Israel is the only country in the world where the size of the immigrant groups is so large that they influence the dominant values. Hofstede explored the Israeli culture through the lens of his Model: Power Distance- Power is decentralized and managers count on the experience of their team members. Respect among the Israelis is earned by proving expertise, and employees expect to be consulted.

35 E. Katzenelson, Connection between parents and their child education system, Journal of Psychoactualia, 2014, Israel Psychological Association, October (Hebrew).

$36 \mathrm{~B}$. Harry, Trends and issues in serving culturally diverse families of children with disabilities, Journal of Special Education, 2002, 36, p. 131-138. 
Individualism- The Israeli society is a blend of Individualist and collectivistic cultures. Small families focus on the parent-children relationship and extended families, with many children are a part of society as well. There is a strong belief in the ideal of self-actualization, loyalty is based on personal preferences and communication is direct and expressive. Masculinity- Israel is neither a clear Masculine nor Feminine society. Performance is highly valued. Managers are expected to be decisive and assertive. Status is often shown, especially by cars, watches and technical devices.

Uncertainty Avoidance- there is an emotional need for rules (even if the rules never seem to work), time is money, people have an inner urge to be busy and work hard, precision and punctuality are the norm, security is an important element in individual motivation. Israelis are talking with their hands, gesticulating and vocal aggressiveness.

Long Term Orientation - Israeli culture has a preference for normative thought. They exhibit great respect for traditions, a relatively small propensity to save for the future, and a focus on achieving quick results.

Israel today is a multi-cultural society, and the country stands to benefit from retaining cultural individuality while striving to achieve a parallel Israeli culture which will absorb and be enriched by the manifold strands that make up the whole. Israel is still a country of immigrants:

- From 1948 to 2014 3,152,146 people from all over the world, immigrate to Israel, ${ }^{37}$

- From 1948 to 2013 1,231,003 people immigrate to Israel from former 40\%USSR, 38

- From 1948 to 2013 92,730 people immigrate to Israel from Ethiopia 3\%. 39

All of these, in addition to thousands of other immigrants from all over the world, have increased the population of the country by over 12 percent in six years

In 2015, the State of Israel consists, according to CBS (2015), 8.345 million people. In 1948 when the state was established, before the waves of immigrants the country had a population of 806,000 people Israel. About $74.9 \%$ are Jews (approximately 6.251 million), approximately $20.73 \%$ are Arab or Druze (about 1.73 million), and the others are about $4.3 \%$.

\footnotetext{
${ }^{37}$ CBS, 2015 http://www.cdc.gov/nchs/nhis.htm http://www.cbs.gov.il/reader/?MIval=cw_usr_view_SHTML\&ID=403.

38 Ibidem.

39 Ibidem.
} 
Migration is an event that involves many difficulties and challenges. The new immigrant is separated from his old lifestyle and people, and should adopt values, norms and new language and unfamiliar to him. Additionally, he has to earn his living and help his children into the education system. ${ }^{40}$ Israel is a land of immigration - a multicultural society with a mosaic of different cultures and the country is often called is a "melting pot" country. ${ }^{41}$

For many years, Israeli society was defined "melting pot": a place where all residents: Jews and non-Jews, religious and secular, are undergoing a process of change and united under a single culture, with no differences between the ethnic groups and having a uniform one-Hebrew-speaking language. The idea of multiculturalism that is sometimes presented as an alternative to "melting pot" is called the "salad bowl approach" or "cultural mosaic". In recent years, the "melting pot" was adopted officially in many countries like in US, Canada Britain including Israel, with the intention to have tolerance to the immigrants from different backgrounds. ${ }^{42}$ It is difficult to measure the impact of government on the degree of assimilation of immigrants and bringing them closer to the "melting pot", for example, offering the immigrants guidance in variety of languages, that are common, and at the same time the immigrant children are encouraged to speak the local language when they were in school.

The "melting pot approach" is not such a tolerant tool because it might bring the immigrants to abandon their culture and they have the necessity to be integrated into mainstream society. Multiculturalism can destroy the fabric of society due to the possibility of ethnic characteristics disappearance. The "salad bowl concept" suggests that the integration of the many different cultures combine like a salad. In the "salad bowl model", various cultures are placed alongside - like salad ingredients - but do not merge into a single homogeneous culture. Each culture keeps its own distinct qualities.

"Cultural mosaic" is the mix of ethnic groups, languages, and cultures that coexist within society. ${ }^{43}$ The idea of a "cultural mosaic" is very similar to the "salad bowl approach", intended to suggest a form

40 S. Lissitsa, Y. Bokek-Cohen, Segmentation of FSU Immigrants according to their sociocultural adjustment patterns for communication and marketing objectives, [in:] Old Roots in New Soil. The Adjustment of FSU immigrants in Israel in the new millennium, Eds. S. Lissitsa, Y. BokekCohen, Ariel University Center of Samaria, 2012, p. 223-239 (Hebrew).

${ }^{41}$ N. Calderon, Multiculturalism versus pluralism in Israel, Haifa University Publishing and Zmora Bitan, Tel Aviv 2000.

42 R. Levine, G. Serbeh-Dunn, Mosaic vs Melting pot, Voices: Publication of the Victoria Immigrant and Refugee Center Society, 1999, 1(4).

${ }^{43}$ B. Kalman, Canada: The Culture, Toronto - New York 2010, p. 4. 
of multiculturalism, different from other systems such as the melting pot, which is often used to describe the ideal of assimilation. ${ }^{44}$

When the state of Israel was funded, the Israeli society intended to be a "melting pot", but during the years, the reality proved that this ideal is impossible and nowadays it is more like "Cultural mosaic", or "salad bowl".

Today, the population of Israel consist of four differences ethnic groups: Sabre, Arabs, and former Soviet Union and Ethiopian immigrants) when each one have its own characteristic.

Cultural Characteristic of the "sabre" family: Israeli immigrant who survived the holocaust, persecution, anti-Semitism, came to join the Jewish collective. They had an obsession of belonging, had a need for intimacy, family feeling, obedience and felt betrayed when they were rejected or humiliated. Subsequently, Aviram ${ }^{45}$ characterizes the modern era in Israel in increasing freedom of the individual, disorder of the value system and weakening of important social institutions that used to help the individual to cope with the difficulties of life (religious communities, neighborhood, family).

Prof $\mathrm{Oz}$ Almog is one of the leading sociologists in Israel. Prof. Almog describes the image of the "Sabra" (native-born) Israeli by eight Features characteristic ${ }^{46}$ : A. Elitism, self-satisfaction and a tendency to talk about themselves. B. Directness- society without masks makes connection very quickly. C. Roughness and disrespect courtesy. D. Identification with the state of Israel, social involvement. E. Sociability, spending time with friends and family. F. Temperament and joy of life. G. Curiosity and initiative highlighting competitiveness, excellence and unconventional thinking. Intelligent, curious, entrepreneurs, with a quick study. H. Non-conformism and criticism - the Israeli is rebellious by nature, not blindly obey authority.

In that context, the new immigrant is facing the ideal "Sabre" stereotype, which is quite different from the way he was brought up, with different cultural values. ${ }^{47}$

Cultural Characteristic of the Ethiopic family: The last decade has witnessed the immigrations of the ancient Jewish community of Ethiopia. p. 31.

${ }_{44}$ A.C. Burgess, T. Burgess, Guide to Western Canada (7th ed.), Globe Pequot Press, 2005,

${ }^{45}$ A. Aviram, Navigating through the Storm: Education in Postmodern Democratic Society, Tel-Aviv 1999 (Hebrew).

46 O. Almog, The sabra: A profile, Am Oved, Tel Aviv 1997, p. 268.

47 N. Calderon, Multiculturalism versus pluralism in Israel, Tel Aviv 2000. 
Ethiopian Jews arrived in Israel in two waves of immigration: in 1984 and in 1991 the total was 22,000 immigrants. ${ }^{48}$ Many Ethiopians immigrant speak their own language - Amharic-language, and they do not speak the Hebrew language. They have no experience of learning in school, and find it difficult to understand the learning difficulties in general and in particular they are not familiar with the term "learning disabilities". Therefore, they oppose to carry out psychological assessments for their children and sometimes there is a suspicion among Ethiopian immigrants, to government institutions in general, and the education system in particular.

In addition, ${ }^{49}$ argues that usually, the professionals are coming from different cultural backgrounds, often alienated from the culture from which the child came from; they have lack of knowledge about the culture of origin and sometimes with patronizing attitudes towards it. Similarly, Artiles \& Trent claim, that when there is not enough information about Ethiopian child among professionals, stereotypes influence their perception and behavior. ${ }^{50}$ It is interesting to note that $15 \%$

of Ethiopian children are referred to special education classes or an integrated classroom, compared with $5.4 \%$ of the other children population who are not Ethiopian. The explanation for the high rate of Ethiopian children in special education is the cultural gap between the largest educational and socialization of young Ethiopian immigrant children who are raised in Israel.

Cultural Characteristic of the former Soviet Union immigrants: From 1948 to 1967, the relations between Jews in the Soviet Union and the State of Israel were limited. Following the Six-Day War, Jewish consciousness among Soviet Jews was awakened, and increasing numbers sought immigration to Israel. As an atmosphere of detente began to pervade international relations in the early 1970s, the Soviet Union permitted significant number of Jews to immigrate to Israel. The influx of immigrants from the Soviet Union in the nineties of the past century is the largest one, about a million people in absolute terms $15 \%$ of the Israeli population as a whole. ${ }^{51}$ It was an extraordinary wave of immigration compared to immigrants in other immigration countries and the uniqueness was not only in quantity but also quali-

48 S. Svirsky, B. Svirsky, The Ethiopian Jews in Israel.

${ }^{49}$ E. Katzenelson, Connection between parents.

50 A.J. Artiles, S.C. Trent, Overrepresentation of minority students in special education a continuing debate, The Journal of Special Education, 1994, 27(4), p. 410-437.

51 S. Lissitsa, Y. Bokek-Cohen, Segmentation of FSU Immigrants according to their sociocultural adjustment .patterns 
ties. The Human capital of the immigrants was impressive. For example, the rate of the highly educated among them exceeds their proportion in the population of the Israeli population. ${ }^{52}$

The term "learning disability" does not exist in Russian language, ${ }^{53}$ therefore, the parents often are reluctant to ignore the diagnose because of the stigma of "diagnosis" or "selection" create a sense that someone is "wrong". Moreover, they often tend to blame the child as "lazy" or "do not invest enough in their studies." Soviet system sorted the children from an early age to those who were qualifies and those who were not qualified and placed them according to these classifications. Hence, all the sorting, classifying or tracking immigrants currently perceived as a threat, and there is a fear that the diagnosis will be written in the student's file, and that will affect his future. In addition, they think that if the learning disabilities in their children will be discovered, their child will not be able to join the army or into higher education and as a result, parents do not know where to turn and who to get help.

Cultural Characteristic of the Arab Israeli family: The Arab population in 2015 includes about 1.73 million Arab Israeli citizens (20\% of the Israeli population). The Arab minority operate in accordance with the Jewish majority in aspects of education, profession, work, etc. ${ }^{54}$ The traditional Arab society is characterized by being Patriarcalic family. The father is the most important source of authority in the family and is the central decision maker in the family. ${ }^{55}$ In addition, the self-image of the family is affected by the family's reputation and its status). Therefore there is agreement for intervention and control about the behavior of family members and their behavior is part of the collective norms and values of the family. Jegatheesan et al., ${ }^{56}$ studied the effect of religious beliefs of a Muslim family and found that it was the basis for calculating the considerations in relation to decisions how to raise their child with learning disability. They found that the first priority is the family's religious beliefs and the gap between care providers and the

52 L. Remennick, Language acquisition, ethnicity and social integration among former Soviet immigrants of the 1990s in Israel, Ethnic and Racial Studies, 2004, 27(3), p. 431-454.

$53 \mathrm{I}$. Shpaizman, The influence of neo-liberal ideas and political conflict on the privatization process of immigrant policy: A comparison of Israel, Canada and the Netherlands, Maastricht 2010 (18-20 February).

54 I. Abu Saad, In a Multicultural Education and the Arab Minority in Israel, [in:] Education in a multicultural society, Ed. P. Pery, Haifa 2007 (Hebrew).

${ }_{55}$ M.M. Hay-Yahia, Attitudes of Arab women toward different patterns of coping with wife abuse, Journal of Interpersonal Violence, 2002, 17, p. 748.

56 B. Jegatheesan, P.J. Miller, S.A. Fowler, Autism from a religious perspective: A study of parental beliefs in South Asian Muslim immigrant families, Focus on Autism and Other, 2010. 
family was evident due to cultural differences. In a similar way Pierse et al.,57 identified differences in culture and language as a barrier for communication with the Muslim family.

\section{The implication of parents' attitudes toward their child Learning Disability}

There is no dispute among the various researchers that parental attitudes have tremendous impact on the determination about the way their child should be taken care and it is dictated by their decision. ${ }^{58}$ Sometimes it is compatible with the recommendations of the school professionals and sometimes it contradicts the committee's recommendation. There is a great importance of cooperation, honesty, openness and mutual trust between parents and school staff, and it is critical, especially for the promotion and progress of the LD child. Differences between the parents attitudes can be also reflected in school in many ways such as: the quality of the equipment the child bring to school, the quantity and quality of food, the way he dress, and of course, parental participation in school and classroom activities, like coming to meetings, helping in doing homework and more.

The benefits from the research will be: A. a change will be made in the settings of the special education classes (adding sociologists' considerations and not only psychological). B. New disciplines of training programs will be introduce of for new teachers. C. a new angle of vision will be offered for training the parents and the educational staff. D. Government and local committees will benefit from this information that will be based on comprehensive qualitative academic research.

Finally, there is no doubt that it is not only a national issue, the author believe that international educational conferences dealing with changing trends in education, might find great interest for this new and unique information as well as local councils.

In summary. Israel is an immigration country that include groups of different ethnicity that each one of them have their own habits, perceptions, believes, attitudes and behaviors that we should understand, respect and

57 A.R. Pierce, US "Partnership" with the Egyptian Muslim Brotherhood and its Effect on Civil Society and Human Rights, Society, 2014, 51(1), p. 68-86.

$58 \mathrm{E}$. Katzenelson, Connection between parents and their child education system, Journal of Psychoactualia, 2014, Israel Psychological Association, October (Hebrew); T. Heiman, An examination of peer relationships. 
plan the way of cooperation with them accordingly. An outline of the research study was presented and these data strengthen the vital need to research the aspect of cultural diversity concerning the implication of parents' attitudes toward their child Learning Disability for the wellbeing of the family and the society.

The proposed study claim that it is necessary to recognize the sociological motives, including the cultural differences within the attitudes of the parents of the LD child that ultimately may affect the quality of the plan care and support, and it is the author's wish to find significands results and insight that will be demonstrated.

\section{BIBLIOGRAPHY}

Abu Saad I., In a Multicultural Education and the Arab Minority in Israel, [in:] Education in a multicultural society, Ed. P. Pery, Department of Education, Haifa University, Haifa 2007 (Hebrew).

After A., Haytav Y., Weizman A., Tiani S., Psychiatry of the child, 1999.

Almog O., The sabra: A profile, Am Oved, Tel Aviv 1997.

Artiles A.J., Trent S.C., Overrepresentation of minority students in special education a continuing debate, The Journal of Special Education, 1994, 27(4).

Aviram A., Navigating through the Storm: Education in Postmodern Democratic Society, Series Futurism in Education, Massada, Tel-Aviv 1999 (Hebrew).

Benn R., Akiva T., Arel S., Roeser R.W., Mindfulness training effects for parents and educators of children with special needs, Developmental Psychology, 2012, 48(5).

Blumer H., Symbolic interaction: perspective and methods, Englewood Cliffs, Prentice-Hall, New York 1969.

Brown M., MacArthur J., McKechanie A., Mack S., Hayes M., Fletcher J., Learning Disability Liaison Nursing Services in south-east Scotland: a mixed-methods impact and outcome study, Journal of Intellectual Disability Research, 2012, 56(12).

Burgess A.C., Burgess T., Guide to Western Canada (7th ed.), Globe Pequot Press, 2005.

Büttner G., Hasselhorn M., Learning disabilities: Debates on definitions, causes, subtypes, and responses, International Journal of Disability, Development and Education, 2011, $58(1)$.

Calderon N., Multiculturalism versus pluralism in Israel, Haifa University Publishing and Zmora Bitan, Tel Aviv 2000.

CBS, 2015 http://www.cdc.gov/nchs/nhis.htm http://www.cbs.gov.il/reader/?MIval= cw_usr_view_SHTML\&ID=403.

Cornwall A., Bawden H.N., Reading Disabilities and Aggression A Critical Review, Journal of Learning Disabilities, 1992, 25(5).

Danino M., Shechtman Z., Superiority of group counseling to individual coaching for parents of children with learning disabilities, Psychotherapy Research, 2012, 22(5).

Dyson L.L., The experiences of families of children with learning disabilities: Parental stress, family functioning, and sibling self-concept, Journal of learning disabilities, 1996, 29(3). 
Emerson E., Commentary: childhood exposure to environmental adversity and the well-being of people with intellectual disabilities, Journal of Intellectual Disability Research, 2013, 57(7).

Gumpel T.P., Sharoni V., Current best practices in learning disabilities in Israel, Learning Disabilities Research \& Practice, 2007, 22(3).

Hall S.S., Burns D.D., Reiss A.L., Modeling family dynamics in children with Fragile X syndrome, Journal of Abnormal Child Psychology, 2007, 35.

Harry B., Trends and issues in serving culturally diverse families of children with disabilities, Journal of Special Education, 2002, 36.

Hay-Yahia M.M., Attitudes of Arab women toward different patterns of coping with wife abuse, Journal of Interpersonal Violence, 2002, 17.

Heer K., Larkin M., Burchess I., Rose J., The cultural context of care-giving: qualitative accounts from South Asian parents who care for a child with intellectual disabilities in the UK, Advances in Mental Health and Intellectual Disabilities, 2012, 6(4).

Heiman T., Friendship quality among children in three educational settings, Journal of Intellectual and Developmental Disability, 2000, 25(1).

Heiman T., An examination of peer relationships of children with and without attention deficit hyperactivity disorder, School Psychology International, 2005, 26(3).

Hofstede G., Dimensionalizing cultures: The Hofstede model in context, Online readings in psychology and culture, 2011, 2(1).

Hofstede G., http://geert-hofstede.com/israel. html from Hofstede center, operated by itim international, 2015.

Igel C., Malichi S., Special Education Law - Social, Value-Oriented, and Professional Reflection in the Shaping of Policy, [in:] Integrating: Learning with Handicaps in the Educational Systems, Eds. S. Reiter, Y. Lazer, G. Avisar, Achva, Haifa 2007 (Hebrew).

Jacobs M., Woolfson L.M., Hunter S.C., Attributions of Stability, Control and Responsibility: How Parents of Children with Intellectual Disabilities View their Child's Problematic Behaviour and its Causes, Journal of Applied Research in Intellectual Disabilities, 2016, 29(1).

Janus M., Kopechanski L., Cameron R., Hughes D., In transition: Experiences of parents of children with special needs at school entry, Early Childhood Education Journal, 2008, 35(5).

Janus M., Lefort J., Cameron R., Kopechanski L., Starting kindergarten: Transition issues for children with special needs, Canadian Journal of Education [Revue canadienne de l'éducation], 2007.

Jegatheesan B., Miller P.J., Fowler S.A., Autism from a religious perspective: A study of parental beliefs in South Asian Muslim immigrant families, Focus on Autism and Other, 2010.

Kalman B., Canada: The Culture, Crabtree Pub, Crabtree Publishing Company, Toronto New York 2010.

Katzenelson E., Connection between parents and their child education system, Journal of Psychoactualia, 2014, Israel Psychological Association, October (Hebrew).

Kemp G., Smith M., Segal J., Learning Disabilities and Disorders. Retrieved March 29, 2015, from http://www.helpguide.org/articles/learning-disabilities/learningdisa bilities-and-disorders.htm

Landerl K., Fussenegger B., Moll K., Willburger E., Dyslexia and dyscalculia: Two learning disorders with different cognitive profiles, Journal of Experimental Child Psychology, 2009, 103(3).

Lange K.W., Reichl S., Lange K.M., Tucha L., Tucha O., The history of attention deficit hyperactivity disorder, ADHD Attention Deficit Hyperactivity Disorders, 2010, 2(4). 
Levine R., Serbeh-Dunn G., Mosaic vs Melting pot, Voices: Publication of the Victoria Immigrant and Refugee Center Society, 1999, 1(4).

Lissitsa S., Bokek-Cohen Y., Segmentation of FSU Immigrants according to their socio-cultural adjustment patterns for communication and marketing objectives, [in:] Old Roots in New Soil. The Adjustment of FSU immigrants in Israel in the new millennium, Eds. S. Lissitsa, Y. Bokek-Cohen, Ariel University Center of Samaria, 2012 (Hebrew).

Margalit M., Almougy K., Classroom behavior and family climate in students with learning disabilities and hyperactive behavior, Journal of Learning Disabilities, 1991, 24(7).

Margalit M., Tur-Kaspa H., LD: A multi-dimensional neurodevelopment model, Psychology, $1998,7$.

Ministry of Education, Ministry of health MOE - the special education law, Israel 1988.

Modlinger I., Liku'ye limida shel hasafa ha'ktuvah [Learning Disabilities of Written Language], 2005 (Hebrew) http:// techedu.huji.ac.il/learning/language/language5.htm

NAEYC, A position statement of the National Association for the Education of Young Children Developmentally Appropriate Practice in Early Childhood Programs Serving Children from Birth through Age, 2009, https://www.naeyc.org/files/naeyc/file/positions/ PSDAP.pdf

Nakash O., Nagar M., Danilovich E., Bentov-Gofrit D., Lurie I., Steiner E., Levav I., Ethnic disparities in mental health treatment gap in a community-based survey and in access to care in psychiatric clinics, International Journal of Social Psychiatry, 2013.

National Joint Committee on Learning Disabilities, Comprehensive assessment and evaluation of students with learning disabilities, 2010, Retrieved from www.ldonline.org/njcld.

OECD, Israel population, Israel 2015, p. 223 https://www.oecd.org/israel/going-forgrowth-israel-2015.pdf

Pierce A.R., US "Partnership" with the Egyptian Muslim Brotherhood and its Effect on Civil Society and Human Rights, Society, 2014, 51(1).

Pitoniak M.J., Royer J.M., Testing accommodations for examinees with disabilities: A review of psychometric, legal, and social policy issues, Review of Educational Research, 2001, 71(1).

Remennick L., Language acquisition, ethnicity and social integration among former Soviet immigrants of the 1990s in Israel, Ethnic and Racial Studies, 2004, 27(3).

Roberts C., Mazzucchelli T., Taylor K., Reid R., Early intervention for behaviour problems in young children with developmental disabilities, International Journal of Disability, Development and Education, 2003, 5.

Rous B., Hallam R., Harbin G., McCormick K., Jung L.A., The transition process for young children with disabilities: A conceptual framework, Infants and Young Children, 2007, 20(2).

Shimshoni R., Brenner A., Learning skills for learners with learning disabilities, The new studio echo, 2004 (Hebrew).

Shpaizman I., The influence of neo-liberal ideas and political conflict on the privatization process of immigrant policy: A comparison of Israel, Canada and the Netherlands, In APPAM International Conference on Migration and Migration Policy, NL, Maastricht 2010 (1820 February).

Simon A., Easvaradoss V., Caregiver Burden in Learning Disability, The International Journal of Indian Psychology, 2015, 2, 3(1).

Spector J.E., Instability of double-deficit subtypes among at-risk first grade readers, Reading Psychology, 2005, 26(3).

Sroubek A., Kelly M., Li X., Inattentiveness in attention-deficit/hyperactivity disorder, Neuroscience Bulletin, 2013, 29(1). 
Svirsky S., Svirsky B., The Ethiopian Jews in Israel: Housing, employment and education, Meida al Shivion, 2002, 11.

Totsika V., Hastings R.P., Emerson E., Lancaster G.A., Berridge D.M., A population-based investigation of behavioral and emotional problems and maternal mental health: Associations with autism spectrum disorder and intellectual disability, Journal of Child Psychology and Psychiatry, 2011, 52(1).

Vellutino F.R., Scanlon D.M., Small S., Fanuele D.P., Response to intervention as a vehicle for distinguishing between children with and without reading disabilities evidence for the role of kindergarten and first-grade interventions, Journal of Learning Disabilities, 2006, 39(2).

World Health Organization, The ICD-10 classification of mental and behavioral disorders: clinical descriptions and diagnostic guidelines, Geneva 1992. 
